\title{
Structure of the Japanese avian community from city centers to natural habitats exhibits a globally observed pattern
}

\author{
Osamu K. Mikami · Katsura Mikami
}

Received: 3 April 2012/Revised: 19 July 2012/ Accepted: 15 August 2012/Published online: 16 September 2012

(C) The Author(s) 2012. This article is published with open access at Springerlink.com

\begin{abstract}
The number of avian species in urban areas throughout the world, particularly in Europe and the USA is low; however, their total density is higher than that observed in surrounding habitats. Nevertheless, it has not been confirmed whether this is true in Japan. Japanese cities have fewer green areas than European and American cities, and Japanese suburbs are likely to face forests on mountain slopes, whereas cities in most other countries face open grasslands, rural areas, or flatlands. These differences could influence the structure of avian diversity from city to native habitat. We compared the number of species and individuals of all species among city centers, suburbs, and forested areas in Japan. Similar to other countries, the structure of avian communities in Japanese cities was dominated by a handful of species, and total abundance was highest among the other environments. This suggests that the underlying mechanism determining the structure of the avian community is the same between Japan and other previously studied countries. However, species richness was not the highest in the intermediate areas, which is typical in Europe and the USA. This is because suburbs face forested areas and moderately urbanized areas are scarce in the study area. The lack of intermediate area is moderately typical in Japan. This difference is important not only for managing avian diversity
\end{abstract}

O. K. Mikami $(\bowtie)$

Department of Biology, Center for Liberal Arts and Sciences, Iwate Medical University, 2-1-1 Nishi-Tokuda, Yahaba-cho,

Shiwa-gun, Iwate 028-3694, Japan

e-mail: osamu.k.mikami@gmail.com

K. Mikami

Japan Bird Research Association, 1-29-9 Sumiyoshi,

Fuchu, Tokyo 183-0034, Japan but also total diversity from the city to native habitats in Japan.

Keywords Avian biodiversity · Biomass ·

Species abundance $\cdot$ Species richness - Urban birds

\section{Introduction}

Expanding urban areas are increasing worldwide (Angel et al. 2005; McDonald et al. 2008). This inevitable expansion has a significant negative effect on biodiversity by reducing and fragmenting native landscapes (Wilcox and Murphy 1985; Marzluff et al. 2001; Chace and Walsh 2006). Many studies have tried to measure the degree of fragmentation and identify ways to minimize it (Grimm et al. 2008).

In these studies, bird-community structures (e.g., species richness and number of individuals) along a gradient of urbanization (e.g., from city centers to the native zone) have often been considered an index of the influence of urbanization on biodiversity (Palomino and Carrascal 2006) and, thus, have been well researched. What has become clear is that the number of species in urban areas is low but the total density of birds is higher than that observed in surrounding habitats (Clergeau et al. 1998; Shochat et al. 2006; Luck and Smallbone 2010). This pattern deviates from that observed in less human-influenced habitats, where the total number of individuals usually positively correlates with species richness. This deviation in urban areas implies that the underlying mechanism determining avian community structure differs between urban areas and less-human-influenced areas (Shochat et al. 2006). As a mechanism for creating this urban-specific pattern, Marzluff (2001) suggested that 
higher resource availability in urban areas supports a higher density of birds. In addition, Shochat et al. (2006) pointed out the importance of the role of species interactions. However, the mechanism remains unclear.

Such an urban-specific pattern with the combination of low species richness and high density is widely observed in urban areas around the world. For example, Madrid, Spain (Palomino and Carrascal 2006); Tucson, AZ, USA (Emlen 1974); Oxford, OH, USA (Beissinger and Osborne 1982); Palo Alto, CA, USA (Blair 1996); San Diego, CA, USA (Crooks et al. 2004); Rennes, France (Clergeau et al. 1998); Orebro, Sweden (Sandström et al. 2006); and large areas in Finland (Jokimäki et al. 1996). However, it has not been confirmed whether this pattern is observed in Japan. The characteristics of urban areas in Japan and those in the above countries differ in the following aspects. First, urban areas in Japan, particularly the city centers, have fewer green areas than those of many other countries (Ministry of Land, Infrastructure and Transport 2011). For example, park area for each individual is $4.4 \mathrm{~m}^{2}$ in Tokyo, whereas it

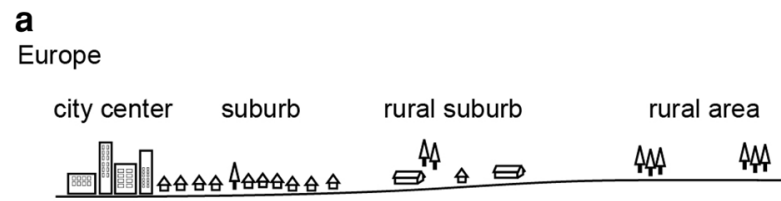

b

Japan

city center suburb forested area on slope of mountain

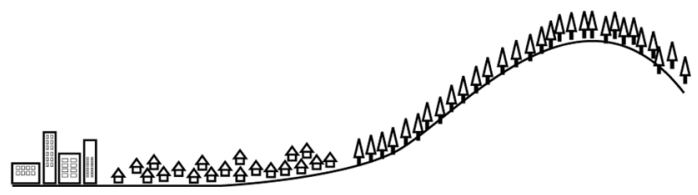

Fig. 1 Typical gradient from a city center to a rural area in Europe (a) and Japan (b) is $26.9 \mathrm{~m}^{2}$ in London and $52.3 \mathrm{~m}^{2}$ in Washington, DC. Second, the gradient from city center to native zone in the above countries often includes the city center, suburbs, rural suburbs, and rural areas (or native zones), and they are located in relatively flat areas (Fig. 1a). In addition, native zones are often grasslands with woods on a flatland (Fig. 1a). In contrast, rural suburbs and rural areas in Japan are not typical, although they exist in prosperous agricultural regions such as Hokkaido. Most Japanese cities, particularly those in western Japan, expand to the foot of mountains, and suburbs often face forested areas on mountain slopes (Fig. 1b). Although we found no academic literature that describes this observation, it was easily confirmed by Google Earth (Fig. 2). Thus, the gradient from city center to natural habitat often consists of city centers, suburbs, and forested areas. These geometric differences provide a way to explore whether the structure of urban avian communities in Japan shows the same pattern observed in the above-mentioned countries.

We compared the number of species and individuals of all species among city centers, suburbs, and forested areas in Japan. We also focused on bird biomass among the three environments, because biomass per unit area is often used as a rough proxy for the energy production of an area. Based on the results, we discuss the similarities and differences in the structure of urban avian communities between Japan and other countries.

\section{Methods}

This study was conducted in June 2006 in Fukuoka city, one of the largest cities in Japan. The study period was the breeding season for birds. We set three 2-km census routes on each of the three environments: city centers, suburbs, and forested areas (Fig. 2). The distribution of the census routes is shown in Fig. 3. The three city center routes were
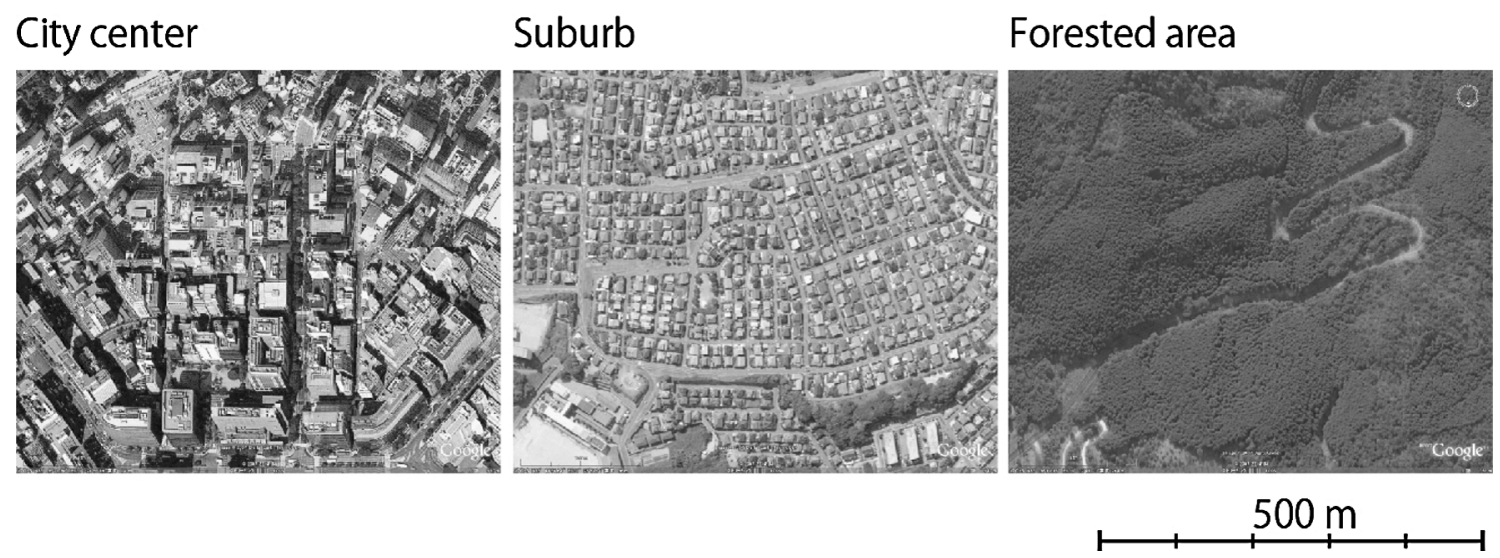

Fig. 2 Aerial photographs illustrating the features of the three studied environments (from Google Earth) 


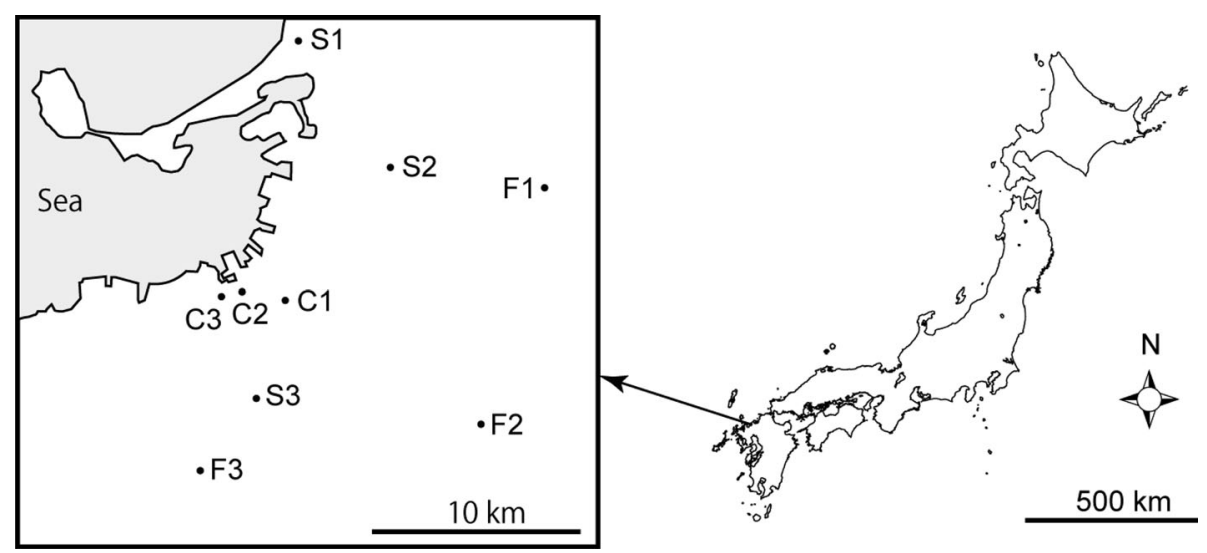

Fig. 3 Locations of the nine tree-environment census routes in Fukuoka City, Japan; $C$ city centers, $S$ suburbs, $F$ forested areas. Exact locations of the centers of each route are as follows: $C 1$ $33^{\circ} 35^{\prime} 22 \mathrm{~N}, 130^{\circ} 25^{\prime} 04 \mathrm{E}, C 233^{\circ} 35^{\prime} 20 \mathrm{~N}, 130^{\circ} 24^{\prime} 02 \mathrm{E}, C 333^{\circ} 35^{\prime} 30 \mathrm{~N}$,

close to each other because only city centers were present there. The width of the census lines was $50 \mathrm{~m}(25 \mathrm{~m}$ at either side from the observer). On each route, we recorded species and number of individuals $2 \mathrm{~h}$ from sunrise on sunny days without wind and rain. Census was conducted one time on each route. We also estimated total biomass of birds recorded on each census route using individual body weights of each species, as shown in Takagawa et al. (2011).

We conducted randomization tests to explore whether each of the three variables (number of species, number of individuals in all species, biomass) was statistically different among the three environments. As an example, the procedure for the number of species was as follows: three values were randomly chosen from nine values, which included the three environments $\times$ the three census routes, and the mean was calculated. Conducting this step 10,000 times created a frequency distribution of the mean values. We used this frequency distribution as a null model that assumed that the mean was not different among the three environments. If each of the means of the observed values (i.e., the mean of the number of species recorded in each environment) was $2.5 \%$ of the smallest value of the frequency distribution, it indicated that the mean of the observed number of species was significantly smaller than the null model. In contrast, if the mean number of species recorded was in the upper $2.5 \%$ of the values, it indicated that the observed number of species was significantly larger than the null model.

\section{Results}

Figure 4 shows the observed species names and the number of individuals in the three environments. One or two $130^{\circ} 23^{\prime} 37 \mathrm{E}, S 133^{\circ} 42^{\prime} 09 \mathrm{~N}, 130^{\circ} 25^{\prime} 28 \mathrm{E}, S 233^{\circ} 38^{\prime} 48 \mathrm{~N}, 130^{\circ} 28^{\prime} 23 \mathrm{E}$, S3 $33^{\circ} 32^{\prime} 48 \mathrm{~N}, \quad 130^{\circ} 24^{\prime} 09 \mathrm{E}, \quad W 133^{\circ} 38^{\prime} 18 \mathrm{~N}, \quad 130^{\circ} 33^{\prime} 14 \mathrm{E}, \quad W 2$ $33^{\circ} 32^{\prime} 05 \mathrm{~N}, 130^{\circ} 31^{\prime} 12 \mathrm{E}, W 333^{\circ} 30^{\prime} 54 \mathrm{~N}, 130^{\circ} 22^{\prime} 06 \mathrm{E}$

species dominated the urbanized areas (i.e., city centers and suburbs), whereas many species were observed in the forested areas, with the number of individuals in each species being relatively small and equal.

Figure 5 shows the randomization test results. The mean number of species was greatest in order of city center $<$ suburb $<$ forested area; the mean value in city centers was significantly lower than the null model and that in the forested areas significantly larger than the null model. The total number of individuals in city centers and suburbs were not different from the null model, but those in the forested areas were significantly lower than the null model. Bird biomass results showed the opposite pattern; biomass was larger in the order of forested area $<$ suburb $<$ city center. The mean biomass in the city centers was larger than the null model, whereas that in the forested areas was smaller.

\section{Discussion}

We found that the structure of avian communities in a Japanese city was dominated by a handful of species and that total bird abundance was higher than that in the other environments. This is the same pattern observed in European and American cities.

The mean number of species was 6.7 in Japanese city centers, 10.0 in suburbs, and 15.3 in forested areas. Although this is not always the case (Jokimäki et al. 2002), previous studies have shown that the values are likely to be similar among countries (Clergeau et al. 2001). The above values are also similar to those in previous studies. For example, a study conducted by Blair (1996) in USA reported seven species in the business district, 16 in a residential area, and 21 in preserves (see Fig. 4 in that 
Fig. 4 Number of individuals of the observed species in the three environments. Data obtained from the three routes are summarized

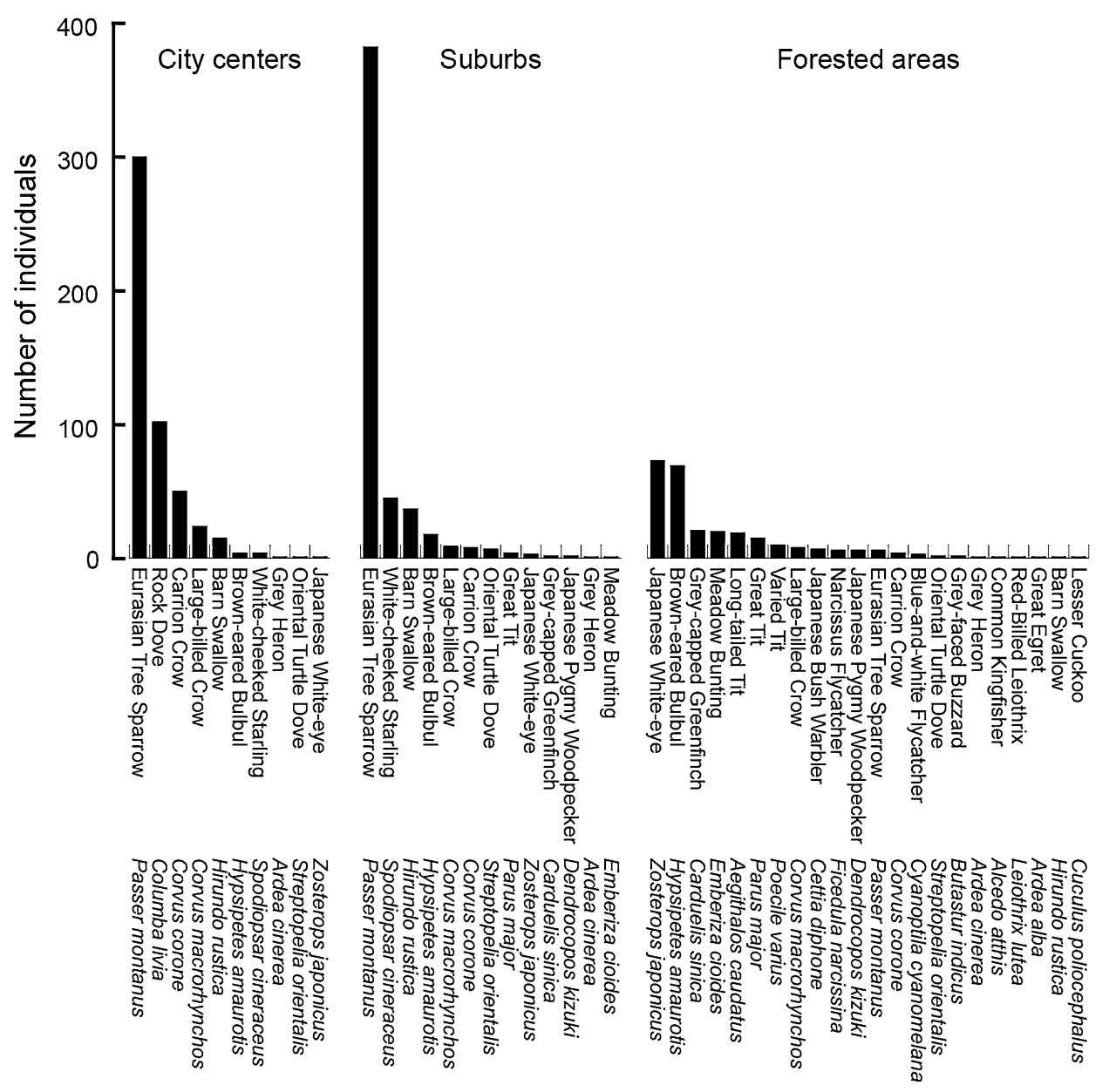

study). In a study conducted by Sandström et al. (2006) in Sweden, 12 species were observed in city centers, 22 in residential areas, and 35 in the periphery (see Table 1 of that study). These values were larger than those in our study, but the proportion among the three environments was similar.

The observed degree of domination by a handful of species in city centers was also similar to that observed in previous studies. In our study, the Eurasian tree sparrow, Passer montanus, occupied $62 \%$ of the total number of individuals in the city centers. In a California city, the rock dove, Columba livia, comprises just $62 \%$ of all individuals (calculated from Table 1 in Blair 1996). In Orebro, Sweden, the house sparrow, P. domesticus (including the Eurasian tree sparrow, due to difficulty in separating them because they create mixed flocks) shares $34 \%$ (Sandström et al. 2006). Beissinger and Osborne (1982) reported that the urban avian community is often dominated by introduced species. The Eurasian tree sparrow is not an introduced species but the rock dove is. Chace and Walsh (2006) stated that urbanization tends to select for omnivores, granivores, and cavity-nesting species. The Eurasian tree sparrow has these characteristics. These consistencies suggest that avian communities in Japanese cities have a similar structure to those in European and American cities, although there are geometric differences among them (Fig. 1).

Although the number of species in our study was smaller than that in the suburbs and forested areas, the biomass in the city centers, which was calculated by body weights of each species, was larger than in the others habitats. A handful of species in the city centers occupied a high proportion of the total biomass. The rock dove, which is $325 \mathrm{~g}$ per individual; the large-billed crow (Corvus macrorhynchos), which is $675 \mathrm{~g}$ per individual, the carrion crow (C. corone) which is $503 \mathrm{~g}$ per individual; and the Eurasian tree sparrow, which is $24 \mathrm{~g}$ per individual, occupied $37 \%, 33 \%, 14 \%$, and $11 \%$, respectively, of the total biomass in city centers. This result is also similar to that of the other countries. For example, the rock dove also occupies $>90 \%$ of the total biomass in a business district of a city in California (Blair 1996). Similar to other countries, city centers in this study area are able to sustain more birds in terms of biomass than are the surrounding habitats. The following mechanisms for creating this pattern were presented in previous studies: (1) resource 

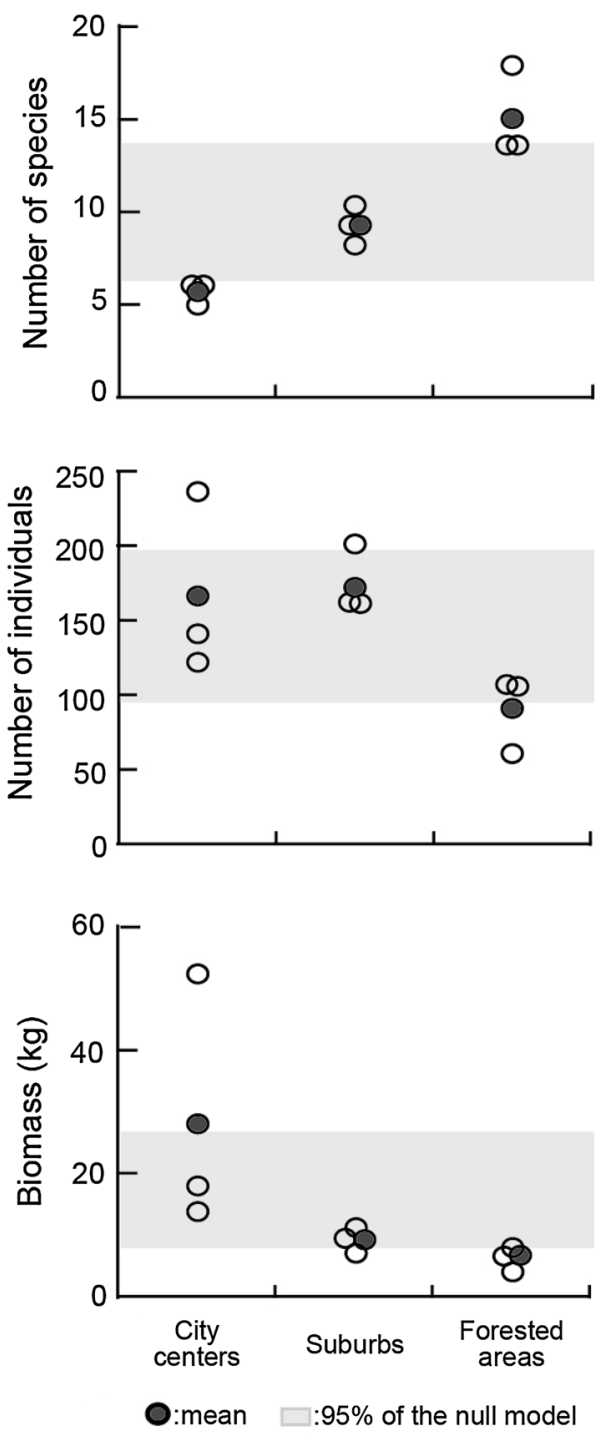

Fig. 5 Number of species, number of individuals of all species, and biomass among city centers, suburbs, and forested areas. The $95 \%$ areas of the null model were obtained from randomization tests

availability is higher in urbanized areas (Marzluff 2001); (2) heat generated in highly urbanized areas decreases energy loss for maintaining basal metabolism of birds that defend against cold stress in the temperate zone (Shochat et al. 2006); (3) although it may fit only two crow species and the rock dove in our study area, some species may move from other areas, leading to an overestimate of density (Blair 1996). In addition to the above-mentioned explanations, the following two factors may be essential in our study area: (1) some urban species have smaller territories than those inhabiting natural habitats, which enables them to live at high density. For example, the Eurasian tree sparrows excludes other individuals from only a limited area around their nest, whereas the great tit, Parus major, which has a similar body size to the sparrow, spends a

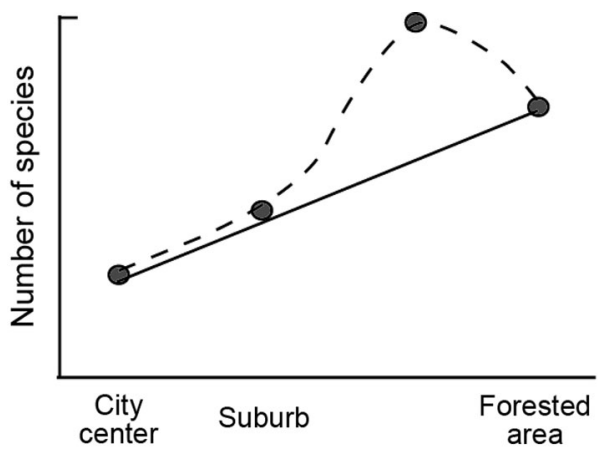

Fig. 6 Two possible trend patterns for the number of species with urbanization. Dashed line shows that species richness is highest at an intermediate stage of urbanization, which is typically observed in Europe and the USA, where previous studies were conducted. The solid line shows the decrease in species richness with urbanization, which may be typical in Japan

significant amount of time and energy defending its territory by singing, vigilance, and chasing other individuals directly; (2) some individuals of the two crow species do not breed because they do not reach breeding age, which decrease the demand for food for each of them. These five explanations are not mutually exclusive. In future studies, the relative significance of each explanation should be addressed.

Despite similarities in the structure of avian communities in city centers between Japan (although only one study), USA, and Europe, species richness in our study was not highest in intermediate areas. In studies conducted in Europe and the USA, the number of species peaks at a moderate level of development, and the trajectory of species richness is similar to the dashed line shown in Fig. 6. This pattern is consistent with the intermediate disturbance hypothesis: environmental heterogeneity in intermediate area promotes species richness (Grime 1973; Horn 1975; Connell 1978). Although the generality of this pattern is still being debated (McKinney 2002), the reason that the species richness monotonically increased against urbanization in the present study is not anything but probably just the lack of an intermediate-like rural suburbs area between the urban areas and the forested areas (Fig. 1b). Of course, we will probably discover the same pattern, such as a dashed line, when we study a gradient that includes an intermediate area. Satoyama is just such an intermediate area, which has unique border zones or areas between mountain foothills and arable land in Japan and includes coppice woodland, paddy fields, and small rivers (see details in Takeuchi et al. 2003). The species richness there is expected to be higher than that of urban or woodland area because Satoyama provides various habitats for birds. Such intermediate areas exist around cities located in big plains. Around cities located in narrow plains between the sea and mountains, however, houses often face the slope of 
mountains without areas of moderate level of development (Fig. 1b). Since Japan is a mountainous country, such a gradient not including an intermediate area is moderately typical. Even if there are intermediate areas, they seem often narrower than that in Europe and the USA. This difference in landscape between Japan, Europe, and the USA is crucial when considering the effect of urban expansion and increasing urban biodiversity in Japan.

In conclusion, we found a consistency in community structure and in characteristics of dominant species among Japanese, European, and USA cities, although there are geographical differences among these countries. This result suggests that the underlying mechanism determining the structure of the avian community is the same between Japan and other previously studied countries. However, the gradient of species richness from city center to the natural habitat differed. The similarities and differences should be a focus of landscape-level planning for species biodiversity.

Acknowledgments This research was supported by the Japan Society for the Promotion of Science grant no. 23780028. This study complies with the current laws of Japan.

Open Access This article is distributed under the terms of the Creative Commons Attribution License which permits any use, distribution, and reproduction in any medium, provided the original author(s) and the source are credited.

\section{References}

Angel S, Sheppard S, Civco D, Buckley R, Chabaeva A, Gitlin L, Kraley A, Parent J, Perlin M (2005) The dynamics of global urban expansion. Transport and Urban Development Department, The World Bank, Washington

Beissinger SR, Osborne DR (1982) Effects of urbanization on avian community organization. Condor $84: 75-83$

Blair RB (1996) Land use and avian species diversity along an urban gradient. Ecol Appl 6:506-519

Chace JF, Walsh JJ (2006) Urban effects on native avifauna: a review. Landsc Urban Plan 74:46-69

Clergeau P, Savard JPL, Mennechez G, Falardeau G (1998) Bird abundance and diversity along an urban-rural gradient: a comparative study between two cities on different continents. Condor 100:413-425

Clergeau P, Jokimäki J, Savard JPL (2001) Are urban bird communities influenced by the bird diversity of adjacent landscapes? J Appl Ecol 38:1122-1134

Connell JH (1978) Diversity in tropical rain forests and coral reefs. Science 199:1302-1310

Crooks KR, Suarez AV, Bolger DT (2004) Avian assemblages along a gradient of urbanization in a highly fragmented landscape. Biol Conserv 115:451-462
Emlen JT (1974) An urban bird community in Tucson, Arizona: derivation, structure, regulation. Condor 76:184-197

Grimm NB, Faeth SH, Golubiewski NE, Redman CL, Wu J, Bai X, Briggs JM (2008) Global change and the ecology of cities. Science 319:756-760

Grime JP (1973) Competitive exclusion in herbaceous vegetation. Nature 242:344-347

Horn HS (1975) Markovian properties of forest succession. In: Cody ML, Diamond JM (eds) Ecology and evolution of communities. Belknap Press, Massachusetts, pp 196-211

Jokimäki J, Clergeau P, Kaisanlahti-Jokimäki ML (2002) Winter bird communities in urban habitats: a comparative study between central and northern Europe. J Biogeogr 29:69-79

Jokimäki J, Suhonen J, Inki K, Jokinen S (1996) Biogeographical comparison of winter bird assemblages in urban environments in Finland. J Biogeogr 23:379-386

Luck GW, Smallbone LT (2010) Species diversity in urban landscapes: patterns, drivers and implications. In: Gaston $\mathrm{K}$ (ed) Urban ecology. Cambridge University Press \& British Ecological Society, pp 88-119

Marzluff JM (2001) Worldwide urbanization and its effects on birds. In: Marzluff JM, Bowman R, Donnelly R (eds) Avian ecology and conservation in an urbanizing world. Kluwer, Norwell, pp 19-47

Marzluff JM (2005) Island biogeography for an urbanizing world: how extinction and colonization may determine biological diversity in human-dominated landscapes. Urban Ecosyst 8:157-177

Marzluff JM, Bowman R, Donnelly R (2001) An historical perspective on urban bird research: trends terms, and approaches. In: Marzluff JM, Bowman R, Donnelly R (eds) Avian ecology and conservation in an urbanizing world. Kluwer, Norwell, pp 1-18

McDonald RI, Kareiva P, Forman RTT (2008) The implications of current and future urbanization for global protected areas and biodiversity conservation. Biol Conserv 141:1695-1703

McKinney ML (2002) Urbanization, biodiversity, and conservation. BioScience 52:883-890

Ministry of Land, Infrastructure and Transport (2011) The situation of urban parks in Japan (in Japanese). http://www.mlit.go.jp/ common/000185195.pdf. Accessed 11 February 2012

Palomino D, Carrascal LM (2006) Urban influence on birds at a regional scale: a case study with the avifauna of northern Madrid province. Landsc Urban Plan 77:276-290

Sandström UG, Angelstam P, Mikusinski G (2006) Ecological diversity of birds in relation to the structure of urban green space. Landsc Urban Plan 77:39-53

Shochat E, Warren PS, Faeth SH, McIntyre NE, Hope D (2006) From patterns to emerging processes in mechanistic urban ecology. Trends Ecol Evol 21:186-191

Takagawa S, Ueta M, Amano T, Okahisa Y, Kamioki M, Takagi M, Takahashi M, Hayama S, Hirano T, Mikami OK, Mori S, Morimoto G, Yamaura Y (2011) JAVIAN Database: a specieslevel database of life history, ecology and morphology of bird species in Japan (in Japanese). Bird Res 7:R9-R12

Takeuchi K, Brown RD, Washitani I, Tsunekawa A, Yokohari M (eds) (2003) Satoyama: the traditional rural landscape of Japan. Springer, Tokyo

Wilcox BA, Murphy DD (1985) Conservation strategy: the effects of fragmentation on extinction. Am Nat 125:879-887 